\title{
CIRCULAÇÃO DE CONTEÚDOS EM PORTAIS E APLICATIVOS: UM ESTU- DO DE CASO DE RÁDIO EXPANDIDO NO RIO DE JANEIRO
}

LUÃN CHAGAS UNIVERSIDADE FEDERAL DO MATO GROSSOCUIABÁ, MATO GROSSO, BRASIL LUAANCHAGAS@GMAIL.COM

LUANA VIANA UNIVERSIDADE FEDERAL DE OURO PRETO OURO PRETO, MINAS GERAIS, BRASIL LVIANA.S@HOTMAIL.COM 


\section{CIRCULAÇÃO DE CONTEÚDOS EM PORTAIS E APLICATIVOS: UM ES- TUDO DE CASO DE RÁDIO EXPANDIDO NO RIO DE JANEIRO}

Resumo: $O$ artigo tem como objetivo analisar como se configura a circulação de conteúdo entre sites e aplicativos das três emissoras mais ouvidas na cidade do Rio de Janeiro (Brasil) no site Rádios.com: a rádio Globo Rio, Super Tupi e CBN. O estudo de caso tem como base as definições do conceito de rádio expandido (KISCHINHEVSKY, 2016) observando as peculiaridades e estratégias dos produtos para diferentes dispositivos.

Palavras-chave: rádio expandido; radiojornalismo; dispositivos móveis; webjornalismo.

\section{LA CIRCULACIÓN DE CONTENIDOS EN PORTALES Y APLICACIONES: UN ESTUDIO DE CASO DE RADIO AMPLIADO EN RÍO DE JANEIRO}

Resumen: El artículo tiene como objetivo analizar cómo se configura la circulación de contenido entre sitios y aplicaciones de las tres emisoras más escuchadas en la ciudad de Río de Janeiro (Brasil) en el sitio Rádios.com: la radio Globo Rio, Super Tupi y CBN. El estudio de caso tiene como base las definiciones del concepto de radio expandido (KISCHINHEVSKY, 2016) observando las peculiaridades y estrategias de los productos para diferentes dispositivos.

Palabras clave: radio ampliado; periodismo radial; aparato móvile, periodismo digital.

\section{THE CIRCULATION OF THE CONTENTS IN THE WEBSITES AND} APPS: A STUDY ABOUT THE CASE OF THE RADIO EXPANDED IN RIO DE JANEIRO

Abstract: The article aims to analyze how to set up the content of movement between sites and applications of the three stations most listened to in the city of Rio de Janeiro (Brazil) in Rádios.com site: Radio Globo Rio, Super Tupi and CBN. The case study is based on expanded radio concept settings (Kischinhevsky, 2016) observing the peculiarities and strategies of products for different devices.

Keywords: expanded radio; radiojournalism; mobile devices; webjournalism 


\section{INTRODUÇÃO}

Em 1922, no Rio de Janeiro, foi registrada oficialmente a primeira transmissão radiofônica em ondas hertzianas no Brasil em comemoração ao centenário da independência. Em 2016, noventa e quatro anos depois, o cenário da radiodifusão na capital fluminense demonstra que esse meio de comunicação conquistou uma pluralidade de espaços, não se limitando ao dial. Em consonância a essas novas configurações do rádio, sua expansão para diferentes dispositivos e a imersão em novas plataformas, percebe-se uma literatura cada vez mais ampliada no Brasil que abarca essas transformações.

A presença desse meio de comunicação na internet, em dispositivos móveis, TVs por assinaturas e outras plataformas, configura o conceito de rádio expandido (KISCHINHEVSKY, 2016) que é fundamental para esse trabalho. Utilizamos, inclusive, as ideias de um rádio hipermidiático (LOPEZ, 2010), que defende que outros elementos podem ser complementos do áudio sem que a produção perca a característica de radiojornalismo.

No mês de março de 2016, a Associação Brasileira de Emissoras de Rádio e Televisão, ABERT, divulgou uma pesquisa na qual estima que entre os anos de 2013 e 2015 o número de rádios com aplicativo exclusivo mais que dobrou: passou de 1.300 para 2.7001. Com base nisso, selecionamos as três emissoras mais ouvidas através da internet no Rio de Janeiro² durante os seis primeiros meses de 2016 para uma análise de seus portais e aplicativos. Portanto, nossos objetos de pesquisa giram em torno das seguintes rádios: Globo Rio 1220 AM 98,1 FM, Super Rádio Tupi FM 96,5 AM 1280 e a CBN FM 92,5 AM 860.

O objetivo central deste trabalho é compreender as estratégias de circulação de conteúdos nas emissoras que disponibilizam suas produções de radiojornalismo em plataformas distintas e se há uma adaptação ou mera transposição de conteúdo, considerando o consumo da informação em diferentes telas, como computador ou em dispositivos móveis - tablets e smar-

1 Dados da pesquisa disponível em: http://www.abert.org.br/web/index.php/notmenu/ item/24868-mobilize-se-abert-estuda-disponibilizar-streaming-para-as-radios Acessado em: 08/04/2016.

2 Dados da pesquisa disponível em: http://www.abert.org.br/web/index.php/notmenu/ item/24868-mobilize-se-abert-estuda-disponibilizar-streaming-para-as-radios Acessado em: 08/04/2016 
tphones. Partimos, inicialmente, da hipótese de que, apesar de serem ofertadas em dispositivos diferentes, as produções radiofônicas não se apropriam das características e potencialidades oferecidas em cada plataforma. O método de pesquisa utilizado lança mão de um estudo de caso (YIN, 2001) das emissoras apresentadas, aliado a uma análise de conteúdo (BARDIN, 1977) a partir da seleção de alguns recursos apresentados nos sites das emissoras e seus respectivos aplicativos.

\section{A OCUPAÇÃO DE NOVOS ESPAÇOS}

É cada vez mais evidente a possibilidade de encontrarmos o rádio em diferentes plataformas, não restrito somente ao dial. O meio está presente nos automóveis, na internet, nos dispositivos móveis, na televisão por assinatura, nas mídias sociais, entre outros. Kischinhevksy (2016) conceitua esse fenômeno como características de um rádio expandido, afirmando, de modo geral, que numa perspectiva não restritiva da radiofonia, entende-se que o meio emprega hoje múltiplas plataformas de difusão.

Com base nisso, recorremos à Lopez (2010) para apresentar a existência de um rádio hipermidiático, o qual "sua construção narrativa apresenta-se como multimídia, mas sempre fundamentada em uma base sonora, por isso se configura como rádio. Esta comunicação sonora (...) é complementada pelo conteúdo multimídia de transmissão multiplataforma" (LOPEZ, 2010, p. 9). Nessa perspectiva, as produções de radiojornalismo possuem como espinha dorsal a linguagem sonora, ainda que combinada com outros elementos com perfil multiplataforma, sem perder a caracterização de conteúdo radiofônico. Esses outros recursos são denominados como elementos "parassonoros" (KISCHINHEVSKY E MODESTO, 2014, p. 19), que incluem "as fotos, vídeos, ícones, infográficos e outras ilustrações de sites de emissoras, toda a arquitetura de interação (botões de compartilhar, etiquetar, curtir, espaços para comentários), textos, hiperlinks", entre outros.

Observa-se, portanto, que outros recursos aliados à linguagem sonora contribuem para a construção de uma narrativa mais abrangente, ao possibilitar a inclusão de imagens, vídeos e textos - elementos antes excluídos do rádio convencional - e ao permitir a interação do usuário com o conteúdo disponibilizado. Visto isso, devemos considerar, ainda, que cada plataforma possui sua própria característica e por consequência oferece utilidades únicas. Os sites, por exemplo, permitem um espaço ilimitado de conteúdo, o que favorece uma narrativa mais aprofundada de determinado tema, além 
de poderem ser acessados por qualquer sistema. Já os aplicativos para dispositivos móveis podem incluir a utilização das funcionalidades dos próprios aparelhos, como a câmera fotográfica, localização espacial por GPS, notificações instantâneas, entre outros.

Esse é o ponto principal dessa pesquisa, comparar os conteúdos entre sites e aplicativos das rádios selecionadas, observando se há apenas uma transposição de conteúdo, definida segundo Salaverria e Negredo (2008, p. 58), de shovelware, ou seja, "informação em massa, sem seleção nem adaptação ao suporte3" ou se há a prática do repurposing, no qual o conteúdo transposto "aproveita a fundo as potencialidades comunicativas próprias da nova plataforma4" (NEGREDO E SALAVERRIA, 2008, p. 59).

Partindo da compreensão sobre os elementos utilizados e os limites impostos pela convergência de mídias no webjornalismo, um estudo de caso foi realizado nos sites e aplicativos das três emissoras mais ouvidas nos seis primeiros meses de 2016 no Rio de Janeiro, a Rádio Globo e Super Rádio Tupi, ambas do segmento talk e a CBN, do segmento all news 5 .

Figura $\mathbf{N}^{\circ}$ 1: Emissoras com mais acessos no Rio de Janeiro em janeiro e fevereiro de 2016

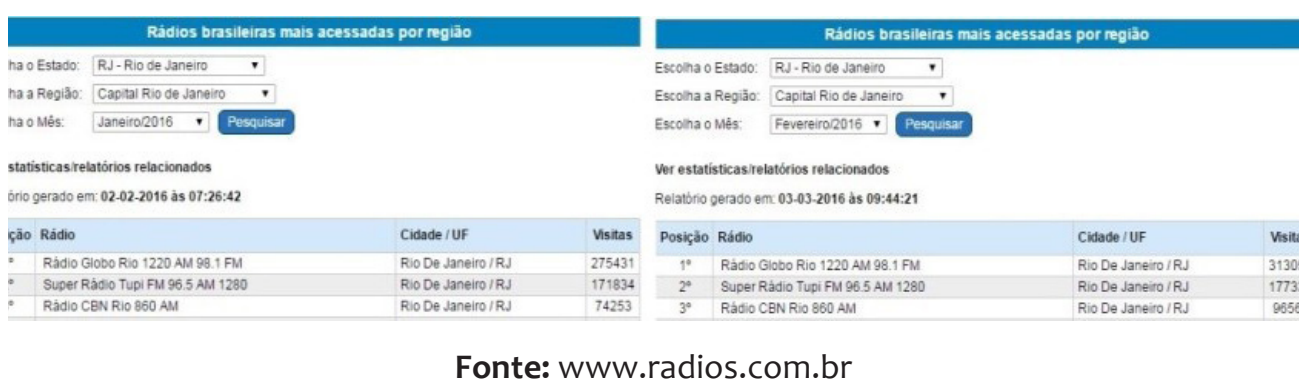

Figura $N^{\circ}$ 2: Emissoras com mais acessos no Rio de Janeiro em março e abril de 2016

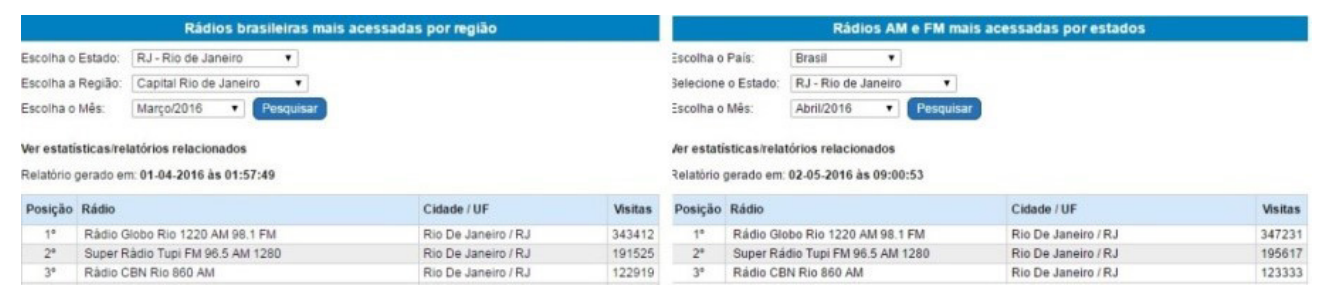

Fonte: www.radios.com.br

3 No original: “Información a granel, sin selección ni adaptación al soporte.”

4 No original: "Aprovecha a fondo las potencialidades comunicativas propias de la nueva plataforma."

5 Dados disponibilizados pelo sistema Rádios.com que mede a quantidade de acessos às emissoras através desse portal. Acessado em: 08/06/2016. 
Figura $\mathrm{N}^{\circ}$ 3: Emissoras com mais acessos no Rio de Janeiro em maio e junho de 2016

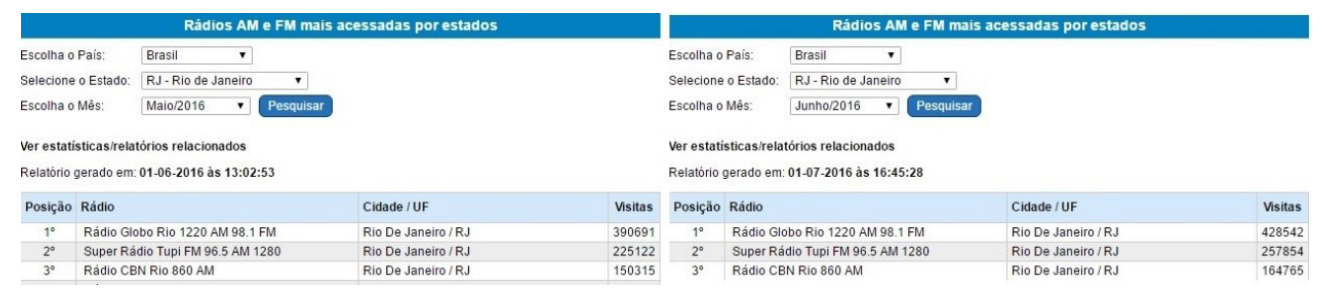

Fonte: www.radios.com.br

O estudo de caso permite organizar os componentes da utilização de sites e aplicativos em categorias que expõem, de acordo com a conceituação teórica, as características utilizadas pelas emissoras na formatação dos produtos online. Para isso, sistematizamos as operações de cada emissora objetivando explorar o conjunto de unidades que se organizam nos portais e aplicativos (BARDIN, 1977).

A divisão em segmentos também facilita a busca por compreender como estão acontecendo os processos e ofertas dentro do contexto compreendido como a fase da multiplicidade da oferta (BRITTOS, 2002). O acirramento das redações ao lado das demissões constantes em emissoras de radiodifusão pode levar a perfis de múltiplas tarefas para a atualização constante dos materiais (FERRARETTO, 2001). As frequências empíricas, unidas a discussão teórica e contextual vão fornecer as bases argumentativas e interpretativas da situação.

A partir desse percurso teórico-metodológico, utilizaremos uma perspectivas para a coleta e categorização dos materiais nas três emissora que dizem respeito ao reconhecimento de que há uma expansão dos conteúdos radiofônicos para o ambiente online, porém em diferentes modalidades. Para encontrar essas similaridades e desencontros na apropriação da narrativa das plataformas, a pesquisa tem como base os conceitos utilizados pelo Grupo de Jornalismo Online (GJOL) da Universidade Federal da Bahia (UFBA).

A inserção do jornalismo no ambiente digital já passou por diversas categorizações e apropriações em diferentes vertentes teóricas. O percurso que propomos neste artigo está alinhado entre as definições propostas por Palacios e Cunha (2014) e Palacios et al. (2002) sobre webjornalismo. Esta inserção, aproximando ao meio ao qual a análise está definida, leva também ao reconhecimento de emissoras inseridas nos contextos de Rádio Expandido e Hipermidiático. Para Palacios et al. (2002), o webjornalismo surgiu com o desenvolvimento de produtos única e exclusivamente para a ambiência da World Wide Web ou então da apropriação das redes telemáticas em 
geral. O termo concorda com as relações adotadas por Murad e Canavilhas (apud PALACIOS et al, 2002), que definem o formato do jornalismo com a nomenclatura do suporte técnico, como por exemplo o radiojornalismo ou telejornalismo.

Essa apropriação aconteceu em três fases ao longo das duas últimas décadas. A primeira é caracterizada pela transposição, com a reprodução dos conteúdos do suporte inicial para a web. Foi neste período que os jornais impressos apenas disponibilizavam suas estruturas impressas no formato online com uma atualização diária. O segundo momento, abordado pelos autores como o da "metáfora", é quando os meios mesmo atrelados a suas indústrias iniciais começam a explorar as potencialidades oferecidas pela rede mundial, como, por exemplo, com o lançamento de webjornais, plantões, atualização via RSS e a abertura de sites específicos de notícias. Já o terceiro e atual momento carrega todas as complexidades e características do ambiente digital que transbordam dos computadores e microcomputadores pessoais para os dispositivos móveis, com transmissões rápidas e a necessária adequação à atualização rápida de imagens, sons e textos (PALACIOS et al., 2002).

Com base em Bardoel e Deuze (2000), Palacios et al. (2002) formulam cinco características das estruturas narrativas no webjornalismo: a) multimidialidade/convergência; b) interatividade; c) hipertextualidade; d) personalização; e) memória. Em 2014, Palácios e Cunha acrescentam mais duas instâncias da produção no ambiente digital - a atualização contínua e a tactilidade - como um recurso específico dos dispositivos móveis, como celulares e tablets.

As características, que serão brevemente apresentadas, refletem as potencialidades oferecidas pela Internet ao jornalismo desenvolvido para a Web. Tais possibilidades não se traduzem necessariamente em aspectos efetivamente explorados pelos sites jornalísticos, quer por razões técnicas, de conveniência, adequação à natureza do produto oferecido ou ainda por questões de aceitação do mercado consumidor. (PALACIOS et al, 2002, p. 4)

Abaixo apresentamos um quadro com características do webjornalismo que serviram como unidades de registro para nossa análise, seguidas com suas respectivas definições:

Quadro 1 - Características do Webjornalismo segundo Palácios et al (2002), Palácios e Cunha (2012) e Palácios e Cunha (2014) 


\begin{tabular}{|c|c|}
\hline Característica & Definição \\
\hline Interatividade & $\begin{array}{c}\text { Possibilidades como troca de e-mails ou então ações que façam } \\
\text { com que o internauta sinta-se parte do processo. }\end{array}$ \\
\hline $\begin{array}{c}\text { Hipertextuali- } \\
\text { dade }\end{array}$ & $\begin{array}{c}\text { Possibilidade de interconectar textos, ligar a outros sites relacio- } \\
\text { nados ao assunto, ou então levar a um aprofundamento do tema } \\
\text { abordado. }\end{array}$ \\
\hline Multimidialidade & $\begin{array}{c}\text { Convergência de diversos formatos como áudio, vídeo, texto, ima- } \\
\text { gens para compor o texto narrativo. }\end{array}$ \\
\hline Personalização & $\begin{array}{c}\text { Capacidade do portal noticioso de oferecer aos usuários a possibili- } \\
\text { dade de customizar a página de acordo com seus interesses. }\end{array}$ \\
\hline Memória & $\begin{array}{c}\text { Possibilidade de armazenamento de textos, áudios, imagens e a } \\
\text { acumulação de informações para posterior acesso ou então para a } \\
\text { recuperação de determinadas informações. }\end{array}$ \\
\hline Atualização con- & $\begin{array}{c}\text { Características da atualização em tempo real forçam o meio a } \\
\text { atualizar minuto a minuto, ou então cada vez mais rápido as infor- } \\
\text { mações disponibilizadas no ambiente digital. }\end{array}$ \\
\hline Tactilidade & $\begin{array}{c}\text { A novidade tecnológica trazida pelos smartphones e tablets onde } \\
\text { as telas sensíveis ao toque levam a novas possibilidades narrativas. }\end{array}$ \\
\hline
\end{tabular}

Fonte: Elaboração própria.

Todas as variáveis, com maior ou menor grau de problematização, também se fazem presentes nos argumentos sobre a necessidade de atender as expectativas dos usuários no momento do acesso aos portais ou aplicativos. Partimos do pressuposto de que as categorizações de Palacios e Cunha (2014) nos permitem enxergar as variáveis que detalham a utilização dos componentes. Para essa análise, em um primeiro momento, são destacados os papéis utilizados pela emissora nos sites em cada um dos elementos expostos nos quadros a seguir.

Quadro 2 - Análise dos sites da Rádio Globo e Super Rádio Tupi

\begin{tabular}{|c|c|c|c|}
\hline \multicolumn{5}{|c|}{ Sites } \\
\hline Elementos & Rádio Globo & Super Rádio Tupi & CBN \\
\hline Interação & Sim & Sim & Sim \\
\hline Hipertextualidade & Sim & Sim & Sim \\
\hline Multimidialidade & Sim & Não & Sim \\
\hline Personalização & Não & Não & Sim \\
\hline Memória & Sim & Sim & Sim \\
\hline Atualização Continua & Sim & Sim & Sim \\
\hline Tactilidade & Não & Não & Não \\
\hline
\end{tabular}

Fonte: Elaboração própria.

O conjunto de elementos foram analisados em diferentes semanas de maio e junho de 2016 nos sites das emissoras Rádio Globo (radioglobo.glo- 
bo.com), Super Rádio Tupi (Tupi.fm) e CBN (cbn.globoradio.globo.com) e mostram o contexto expandido dentro da multiplicidade de canais de postagem das redações. As diferenças encontrada entre os portais é que a utilização da multimidialidade não se faz presente na Super Rádio Tupi e o site da CBN apresenta a possibilidade de personalização com a escolha de podcasts, notícias, editorias e cidades de escuta, como o caso de São Paulo, Rio de Janeiro e Brasília.

Figura ํㅜ 4: Sites Rádios Globo e Tupi
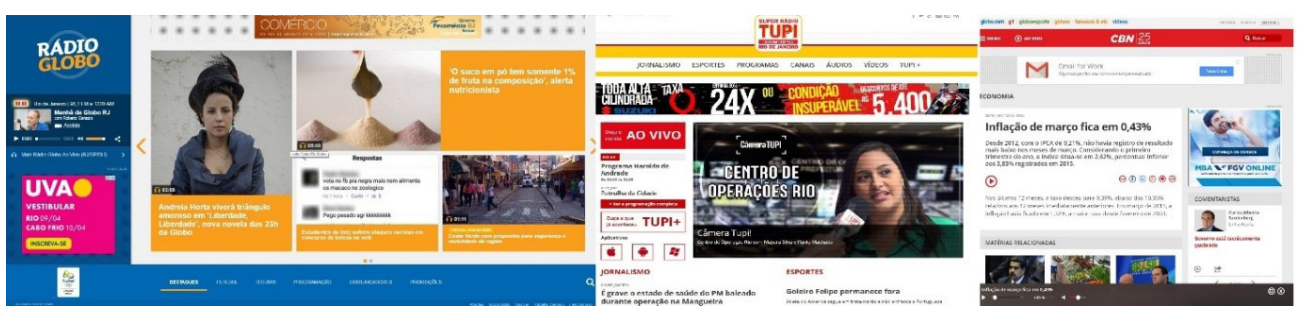

Fonte: www.radioglobo.globo.com, www.tupi.fm e www.cbn.globoradio.globo.com

As diferenças de postagens de conteúdos estão na utilização do áudio. No caso das emissoras do Sistema Globo de Rádio - Globo e CBN -, o áudio aparece como prioridade, há retransmissão das ondas hertzianas acompanhada de câmera no estúdio e áudios que podem ser acessados por links que vêm acompanhados apenas de uma imagem e título da matéria. No caso da Tupi, o áudio também está presente no formato de streaming ao vivo e oferece a possibilidade do internauta assistir imagens do estúdio enquanto ocorre a transmissão. Já os links de notícias que constam nesse site utilizam apenas o texto para informar. Os links de áudios disponíveis são recortes de programas musicais e de entretenimento da emissora.

No caso dos aplicativos das emissoras, utilizamos o mesmo sistema para a exploração das plataformas. Abaixo o quadro resultante da análise:

Quadro 3 - Análise dos aplicativos da Rádio Globo e Super Rádio Tupi

\begin{tabular}{|c|c|c|c|}
\hline \multicolumn{5}{|c|}{ Aplicativos } \\
\hline Elementos & Rádio Globo & Super Rádio Tupi & CBN \\
\hline Interação & Sim & Sim & Sim \\
\hline Hipertextualidade & Não & Não & Sim \\
\hline Multimidialidade & Não & Não & Sim \\
\hline Personalização & Não & Não & Sim \\
\hline Memória & Não & Não & Sim \\
\hline Atualização Contínua & Não & Não & Sim \\
\hline Tactilidade & Sim & Não & Sim \\
\hline
\end{tabular}

Fonte: Elaboração própria.

Em primeiro lugar, destacamos que não há estratégias diferenciadas na 
tactilidade direcionada para smartphones e tablets nos casos da Globo e Super Rádio Tupi. Apesar de serem partes de um mesmo sistema de comunicação, a CBN se mostra diferente da Rádio Globo, apresentando um aplicativo com a presença de todos os aspectos da tabela de análise. Nele é possível personalizar, escolher ou estabelecer um padrão de escuta via streaming ou por demanda, além da atualização no mesmo ritmo do portal da emissora.

Figura $N^{\circ}$ : Aplicativos Rádios Globo e Tupi

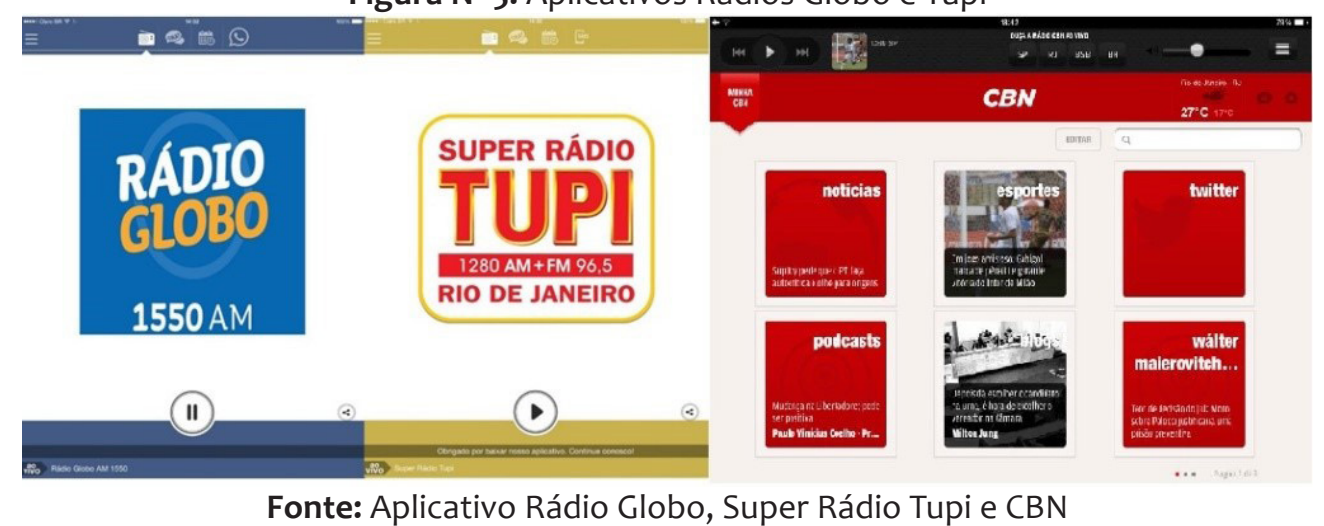

Em um segundo momento, observamos que há uma expansão que vai além da retransmissão do áudio via ondas hertzianas. Nos dois primeiros casos, o botão play aparece como atrativo para o ouvinte, podendo ser escutado enquanto se acessam outros recursos do suporte. Já a CBN, além da escuta, a navegação personalizada e a navegação no aplicativo permitem uma escolha dos conteúdos para escuta. A interação é realizada da mesma forma nos três aplicativos, via e-mail ou via redes sociais, como o Facebook e Twitter. No caso da emissora Globo a inclusão do ícone do Whatsapp é a única diferença.

\section{CONSIDERAÇÕES FINAIS}

Retomamos a expressão dos conceitos de rádio expandido (KISCHINHEVSKY, 2016) e hipermidiático (LOPEZ, 2010) - que norteiam a nossa compreensão sobre a presença do rádio em novas plataformas agregando ao áudio outras linguagens - ao justificar a análise da circulação de conteúdos radiofônicos de cada emissora estudada em duas plataformas diferentes: 0 site e o aplicativo.

Consideramos para análise que as plataformas foram acessadas por dispositivos diferentes: os sites por computador ou notebooks e os aplicativos por dispositivos móveis: smartphones ou tablets. Caso o site de cada emissora fosse acessado por meio desses últimos dispositivos, eles receberiam como característica presente a tactibilidade, desconfigurando a exclusivida- 
de da aparição dessa característica na análise dos aplicativos.

O site da Super Rádio Tupi, como visto, não explora a multimidialidade, sendo esta a única diferença nas unidades de registro encontrada em relação aos sites das emissores da rede Globo. Encontramos muita similaridade na maneira como as duas emissoras do segmento talk do Rio de Janeiro utilizam as plataformas digitais para difusão de conteúdo. A CBN, do segmento all news, utiliza uma estratégia diferenciada, inserindo-se nos sistemas com características variadas, principalmente ao explorar as potencialidades de tablets e smartphones.

Os aplicativos das duas primeiras emissoras do ranking de mais ouvidas apresentam as mesmas análises como resultado, com a presença e ausência dos mesmos elementos. Foi possível perceber que os aplicativos priorizam a retransmissão dos áudios ao vivo em streaming e, quando apresentam conteúdos em texto, são mera reprodução daqueles veiculados pelo site da emissora. De maneira geral, as características do webjornalismo não são encontradas nos aplicativos para dispositivos móveis. O elemento "personalização", presente na CBN - se explorado conscientemente pelas outras emissoras -, ganharia espaço nas produções destinada a estes aparatos, já que a funcionalidade presente nos aparelhos como localizadores geoespaciais poderiam favorecer essa personalização de conteúdo, apesar do aplicativo da CBN possibilitar a escolha de região, como São Paulo, Rio de Janeiro ou Brasília.

Visto isso, observamos que, com exceção Rádio CBN, os conteúdos radiofônicos não foram produzidos explorando as potencialidades das plataformas as quais foram destinadas. Os desenvolvimentos dos produtos multiplataforma também estão condicionados a rotinas de produção onde a convergência profissional é marcada pela diminuição na mão de obra e escassez de recursos nas emissoras. Portanto, consideramos importante uma pesquisa mais aprofundada em relação aos objetos estudados, pois alguns elementos poderiam ter uma relevância maior que outros dentro da análise, reconfigurando algumas das nossas observações.

\section{AGRADECIMENTOS}

Os autores agradecem à Fundação Carlos Chagas Filho de Amparo à Pesquisa do Estado do Rio de Janeiro (FAPERJ), ao Conselho Nacional de Desenvolvimento Científico e Tecnológico (CNPq) e à Universidade Federal de Ouro Preto (UFOP) pelo apoio a suas pesquisas. 


\section{REFERÊNCIAS}

BARDIN, Laurence. Análise de conteúdo. Lisboa: Edições 70, 1977.

BARDOEL, JO. DEUZE, Mark. Network Journalism: converging competences of old and new media professionals, disponível em: http://home.pscw.nl/deuze/pub/9.htm Acessado em: 08/04/2016

BRITTOS, Valério Cruz. O rádio brasileiro na fase da multiplicidade da oferta. Verso \& Reverso. São Leopoldo: Universidade do Vale do Rio dos Sinos, ano 16, n. 35, p. 31-54, jul.-dez, 2002.

FERRARETTO, Luiz Artur. Rádio: veículo, a história e a técnica. Porto Alegre: Sagra Suzzato, 2001.

KISCHINHEVSKY, Marcelo; MODESTO, Cláudia Figueiredo. Interações e mediações, instâncias de apreensão da comunicação radiofônica. Questões Transversais - Revista de Epistemologias da Comunicação, v. 2, p. 12-20, 2014.

KISCHINHEVSKY, Marcelo. Rádio e Mídias Sociais. Rio de Janeiro: Mauad X, 2016.

LOPEZ, Debora Cristina. Radiojornalismo hipermidiático: tendências e perspectivas do jornalismo de rádio all news brasileiro em um contexto de convergência tecnológica. Covilhã: LabcomBooks, 2010.

NEGREDO, Samuel; SALAVERRIA, Ramon. Periodismo integrado: convergencia de medios y reorganización de redacciones. Barcelona: Sol9o Media, 2008.

PALACIOS, Marcos; CUNHA, Rodrigo. A tactilidade como dimensão operacional nos dispositivos móveis: algumas aplicações ao Jornalismo. In: PELLANDA, E.; BARBOSA, S. (Orgs.). Jornalismo e mídias móveis no contexto da convergência. Porto Alegre: EDiPUCRS, 2014.

PALACIOS, Marcos; CUNHA, Rodrigo. A tactilidade em dispositivos móveis: primeiras reflexões e ensaio de tipologia para uma característica agregada ao ciberjornalismo. Contemporânea, Comunicação e Cultura, v.10, n. 3, set-dez, 2012.

PALACIOS, Marcos; MIELNICZUK, Luciana; BARBOSA, Susana; RIBAS, Beatriz; NARITA, Sandra. Um Mapeamento de características e tendências no jornalismo online brasileiro e português. Comunicarte, Aveiro - Portugal, v. 1, n. 2, p. 160-170, 2002. 


\section{Luãn Chagas}

Professor da Faculdade de Comunicação e Artes da Universidade Federal do Mato Grosso (UFMT) e doutorando no Programa de Pós-Graduação em Comunicação (PPGCOM) da Universidade do Estado do Rio de Janeiro (UERJ). E-mail: luaanchagas@gmail.com.

\section{Luana Viana}

Doutoranda em Comunicação pela Universidade Federal de Juiz de Fora (UFJF), Mestre em Comunicação pela Universidade Federal de Ouro Preto (UFOP) e membro do Grupo de Pesquisa Convergência e Jornalismo (PPGCOM/UFOP) e do Grupo de Pesquisa Mediações e Interações Radiofônicas (PPGCOM/UERJ).

E-mail: Iviana.s@hotmail.com. 